\title{
Effects of reduction factor on rain attenuation predictions over millimeter-wave links for $5 \mathrm{G}$ applications
}

\author{
M. Rashid, Jafri Din \\ Wireless Communication Center, School of Electrical Engineering, Universiti Teknologi Malaysia, Malaysia
}

\begin{tabular}{l} 
Article Info \\
\hline Article history: \\
Received Dec 20, 2019 \\
Revised Mar 7, 2020 \\
Accepted Apr 9, 2020 \\
\hline
\end{tabular}

Keywords:

Fifth-generation (5G)

Millimeter-wave (mm-wave)

Path reduction factor

Rain attenuation

Rain intensity

\begin{abstract}
Millimeter-wave will be the strong contender for the terrestrial link using for $5 \mathrm{G}$ networks. So it is imperative to examine these frequency bands to ensure the uninterrupted services when $5 \mathrm{G}$ network is connected in tropical regions. A critical challenge of link-budgeting in mm-wave 5G networks is the precise estimation of rain attenuation for short-path links. The difficulties are further intensified in the tropical areas where the rainfall rate is very high. Different models are proposed to predict rain attenuation, however recent measurements show huge discrepancies with predictions for shorter links at mm-wave. The path reduction factor is the main parameter in the prediction model for predicting total attenuation from specific rain attenuation. This study investigates four path reduction factor models for the prediction of rain attenuation. A comparison was made between these models based on rain attenuation data measured at $26 \mathrm{GHz}$ at $300 \mathrm{~m}$ and 1.3 $\mathrm{km}$ links in Malaysia. All models are found to predict rain attenuation at a $1.3 \mathrm{~km}$ link with minimum errors, while tremendous discrepancies are observed for $300 \mathrm{~m}$ link. Hence it is highly recommended to further investigate the reduction factor model for shorter links less than $1 \mathrm{~km}$.
\end{abstract}

This is an open access article under the $\underline{C C B Y-S A}$ license.

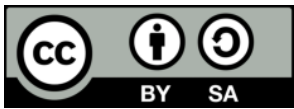

\section{Corresponding Author:}

Jafri Din,

Wireless Communication Center, School of Electrical Engineering,

Universiti Teknologi Malaysia,

81310 UTM Johor Bahru, Malaysia.

Email: jafri@utm.my

\section{INTRODUCTION}

The Worldwide continuous demand for data on wireless communication systems having user ubiquitous access requires a high-speed data rate and a large bandwidth to fulfill the requirement uninterruptedly. 5th generation (5G) millimeter-wave (mm-Wave) communication system is coming forth technology which will provide efficient mmWave spectrum utilization to provide high-speed data rates and large bandwidth. Precipitation is a prevailing source of attenuation at mm-wave bands [1]. Attenuation due to precipitation at frequencies over $10 \mathrm{GHz}$, mostly extends to outages that compromise the accessibility and performance of the mm-wave links, which leads to the most critical challenges for mm-wave link design. The information of rain fade is the basic requirement to establish a reliable and uninterrupted network for 5G links [2-3]. Precipitation is a notable obstruction that hinders the mm-wave signals propagating from the transmitter link to the receiver link. The transmitting signal can be ingested, dissipated, depolarized and diffracted by precipitation. This outcome causes extra fading to the transmitted signals. The impact of high rain intensity turns out to be a further vital issue when the rain intensity rate, the transmitted frequency band or the path length between the transmitter and the receiver more increase [4-5]. 
To predict the attenuation due to rain correctly, the pattern of raining events such as the distribution of rain within the rain cell needs to be investigated. These phenomena reduce the effective length of raining along the propagation path [6]. The amount of attenuation due to precipitation measurements is determined by attenuation due to precipitation per unit of path length. The measure of attenuation due to precipitation per unit of path length characterized as $\gamma_{R}$, specific rain attenuation estimated in $[\mathrm{dB} / \mathrm{km}]$. Assessing the $\gamma_{R}$ principally relies upon the rain intensity, frequency regression coefficients, and the type of polarization. Consequently, the specific rain attenuation, $\gamma_{R}$ applying the coefficients of frequency-dependent carried in (1),

$$
\gamma_{R}=k R^{\alpha} \quad \mathrm{dB} / \mathrm{km}
$$

Where $R(\mathrm{~mm} / \mathrm{h})$ is the rainfall rate for a given year. From the measurement at the point of location site as mentioned, $0.01 \%$ of the time, the one-min. rainfall intensity was found $116 \mathrm{~mm} / \mathrm{h}$. The coefficient value of $k$ and $\alpha$ are dependent on the value of the frequency, $f(\mathrm{GHz})$, the polarization of the wave and distribution of the raindrop size [7-9]. Attenuation due to rain on a line-of-sight (LOS) path can be expressed in (2)

$$
A=\gamma_{R} d_{e f f}=\gamma_{R} \times d \times r \quad \mathrm{~dB}
$$

Where $d_{\text {eff }}$ is the effective path length over which rain rate is considered uniform and $d$ is the actual path length in $\mathrm{km}$. The horizontal path reduction factor, $r$ which accounts for the horizontal inhomogeneity of rain along the propagation path. The distance between the transmitter and receiver which is known as path length, $d$ is another parameter that attenuates signals of mm-waves during precipitation.

Precipitation is not invariantly dispersed along the total path length. In this way, the total distance is not the same as the effective distance [10-12]. This estimation is dependent on precipitation dispersion. Accordingly, attenuation of signal due to rainfall rate determined as a function of the effective path length. At the point when this distance expands, it implies the precipitation will comprehend a more area between links, leads to more signal fading. Most of the measurements for the mm-wave terrestrial link are concentrated on effective path length and considered path reduction factors (less than 1) as the main part of the rain fade estimation. These prediction models are used as a way of 'averaging out' the spatial inhomogeneity of rainfall rate that is uniformly distributed along the propagation path of $1 \mathrm{~km}$ and named as specific attenuation in $\mathrm{dB} / \mathrm{km}$. Various research had examined and demonstrated this issue such as AbdulRahman et al, Lin et al, da Silva Mello et al. It was perceived that the additional attenuation caused by rain is straightforwardly proportional to the active distance between the links [13]. To anticipate the aggregate sum of attenuation being caused by precipitation such as an mm-wave link might undergo, a path reduction factor that is required to count the variability of rainfall rate results along the propagation path for a short distance. Interestingly, rain-induced attenuation predicted by utilizing ITU-R P.530-17 largely overestimates the measured data for short path length [14-15]. This is due to the inclusion of distance factor $r$, the behavior of which is found inconsistent for path lengths less than $1 \mathrm{~km}$. Hence, a modification for distance factor $r$ in ITU-R P530.17 is required for accurate prediction of short links in a tropical climate [16].

\section{REDUCTION FACTOR MODELS}

\subsection{ITU-R P-530-17}

Precipitation happens in a range where the rainfall rate is more at the focal point of the rain falling area and diminishes quickly near to the boundary. It is because of the precipitation natural characteristics, which is enormously convectional. Accordingly, when anticipating the measure of attenuation because of rainfall that an mm-wave network may endure, a reduction factor, $r$ is essential for the unevenness of rainfall rate happening along the path between the terrestrial links. Thus, the reduction factor, $r$ is a significant parametric quantity for the estimation of signal fade due to rain. From ITU-R P.530.17 [17], this $r$ which is known as the reduction factor is given by (3)

$$
r=\frac{1}{\left(0.477 \times d^{0.633} \times R_{0.01}^{0.073 \alpha} \times f^{0.123}\right)-10.579(1-\exp (-0.024 d))}
$$

Where frequency, $\mathrm{f}$ in $\mathrm{GHz}$ and $\alpha$ is mentioned earlier in (1). The value of $r$ can be highest equal to 2.5, so use the value of $r$ is 2.5 , when the denominator value of the (3) is less than 0.4 . 
The rain-induced attenuation for different percentages of time, $\mathrm{p}$ in the range from $0.001 \%$ to $1 \%$ derived by the power-law relationship given by (4)

$$
\frac{A_{p}}{A_{0.01}}=C_{1} p^{-\left(C_{2}+C_{3} \log _{10} p\right)}
$$

With

$$
\begin{aligned}
& C_{1}=\left(0.07^{C_{0}}\right)\left[0.12^{\left(1-C_{0}\right)}\right] \\
& C_{2}=0.855 C_{0}+0.546\left(1-C_{0}\right) \\
& C_{3}=0.139 C_{0}+0.043\left(1-C_{0}\right)
\end{aligned}
$$

Where

$$
C_{0}= \begin{cases}0.12+0.4\left[\log _{10}(f / 10)^{0.8}\right] & f \geq 10 \mathrm{GHz} \\ 0.12 & f<10 \mathrm{GHz}\end{cases}
$$

ITU recommended applying this model around the world, by giving measured rainfall rate data at the regionally or by applying the ITU recommended map. It is applicable for estimation of rain attenuation at any frequency somewhere in the range of 1 and $100 \mathrm{GHz}$ with a limited distance till $60 \mathrm{~km}$.

\subsection{Abdulrahman model}

AbdulRahman [18] developed a model to estimate the path reduction factor as expressed in (7)

$$
r\left(R_{0.01}, d\right)=\frac{1}{1+\left[\frac{d}{2.6379\left(R_{0.01}\right)^{0.21}}\right]}
$$

Where $d$ represents the actual distance between the transmitter and receiver of the link and $\mathrm{R}_{0.01}$ is the rain rate at $0.01 \%$ percentage of the time. This model using multiple non-linear regression techniques. The rain-induced attenuation for different percentages of time, $\mathrm{p}$ in the range from $0.001 \%$ to $1 \%$ derived by (8)

$$
A_{\% p}=\gamma_{R} \times d_{e f f}=\left\{k\left(R_{\% p}\right)^{\alpha}\right\} \times \frac{d}{1+\left[\frac{d}{2.6379\left(R_{0.01}\right)^{0.21}}\right]}
$$

\subsection{Lin model}

This model [19] reported in some measure associate with variability of rainfall rate along the propagation path. The path reduction factor, $r$ is given by this model is shown in (9)

$$
r=\frac{1}{1+\left(\frac{d}{d(R)}\right)} \quad \text { where, } \quad d(R)=\frac{2636}{R-6.2}
$$

Where $d$ represents the actual distance between the links and $\mathrm{R}$ is the rainfall rate. The rain-induced attenuation for different percentages of time, $\mathrm{p}$ in the range from $0.001 \%$ to $1 \%$ derived by (10) 


$$
A_{\% p}=\gamma_{R} \times d_{e f f}=\left\{k\left(R_{\% p}\right)^{\alpha}\right\} \times \frac{d}{1+\left(\frac{d}{d(R)}\right)}
$$

\subsection{Da silva mello model}

This model [20-21] practice the numerical coefficients that are determined for effective rainfall rate and across identical rain cell distances that were acquired by various nonlinear regressions, utilizing the accessible measured data. The path reduction factor for this model is shown in (11)

$$
r=\frac{1}{1+\left(\frac{d}{d_{0}\left(R_{p}\right)}\right)} \quad \text { where, } \quad d_{0}=119 R^{-0.244}
$$

Here $d$ is the actual path length between the links and $d_{0}$ represents equivalent rain cell diameter. The rain-induced attenuation for different percentages of time, $p$ in the range from $0.001 \%$ to $1 \%$ derived by (12)

$$
\begin{aligned}
& A_{\% p}=\gamma_{R} \times d_{\text {eff }}=k\left[R_{\text {eff }}\left(R_{p}, d\right)\right]^{\alpha} \times \frac{d}{1+\left(\frac{d}{d_{0}\left(R_{p}\right)}\right)} \\
& R_{\text {eff }}=1.763 R^{0.753+\frac{0.197}{d}}
\end{aligned}
$$

Where, $R_{\text {eff }}$ is the effective rainfall rate, a function of $d$ and $R_{p}$. The regression coefficients of (13) were obtained by multiple nonlinear regressions, using the currently measured data in the ITU-R databanks.

\section{INVESTIGATION OF PATH REDUCTION FACTOR}

Rain occurs in cells that are mostly convective by nature, that causes the rain rate to be higher at the center of the rain cell and taping rapidly at the edge. This eventually leads to unequal dispersion of rain in areas that are experiencing precipitation. Hence, the need to use the path reduction factor as a parameter for the calculation of attenuation due to rain is essential. The reduction factors $r$ proposed by 4 models are investigated for path length less than $1 \mathrm{~km}$ and more $1 \mathrm{~km}$ and presented in the following section.

\subsection{Variations of $\boldsymbol{r}$ for less than $1 \mathrm{~km}$}

The reduction factor $r$ proposed by ITU-R [17], AbdulRahman [18], Lin [19] and da Silva Mello [20] models are investigated based on (3-4, 7-12) and shown in Figure 1. From Figure 1, it is observed that the value of the reduction factor is almost constant with value 1 for AbdulRahman, Lin and da Silva Mello Model. But for ITU-R it shows the value of $\mathrm{r}$ increases exponentially for path length less than $1 \mathrm{~km}$. For 300 meter, the value of $\mathrm{r}$ is 2.548 for the ITU-R model, 0.959 for AbdulRahman model, 0.992 for da Silva Mello model and 0.987 for Lin Model.

\subsection{Variations of $\boldsymbol{r}$ for greater than $1 \mathrm{~km}$}

The reduction factor $\mathrm{r}$ proposed by ITU-R, AbdulRahman, Lin and da Silva Mello models are investigated based on (3-4, 7-12) and shown in Figure 2. From Figure 2, it is observed that the value of the reduction factor is almost linearly decreasing with the increase of path length for AbdulRahman, da Silva Mello and Lin model. But ITU-R model shows the value of reduction factor exponentially decreasing with the increase of path length. For $1.3 \mathrm{~km}$, the value of $\mathrm{r}$ is 1.163 for the ITU-R model, 0.846 for the AbdulRahman model, 0.948 for Lin Model and 0.966 for the da Silva Mello model. 


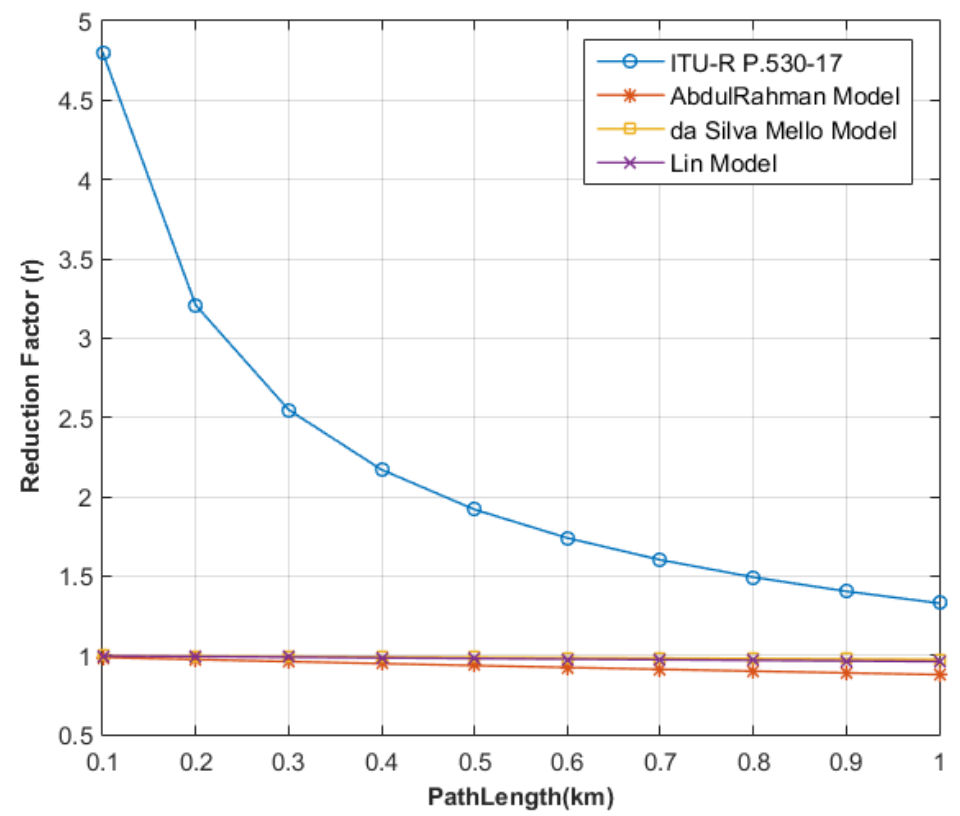

Figure 1. Comparison of reduction factor with path length proposed by different prediction models for less than $1 \mathrm{~km}$ path length

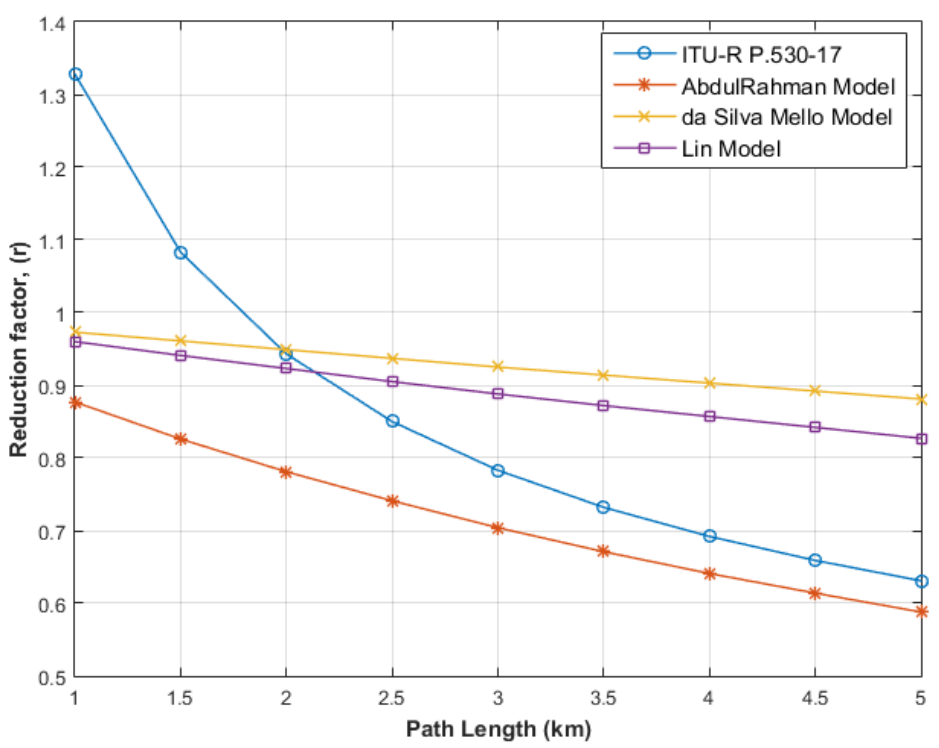

Figure 2. Comparison of reduction factor with path length proposed by different prediction models for greater than $1 \mathrm{~km}$ path length

\section{RAINFALL RATE AND ATTENUATION MEASUREMENT}

Here in the article, two years of continuous measurement was conducted to research the effect of precipitation on the propagation of millimeter-wave links at $26 \mathrm{GHz}$. Block diagram of the experimental setup for data collections at UTM is shown in Figure 3. Two Ericsson links were set up at the operating frequency of $26 \mathrm{GHz}$ in the university premises at Johor Bahru city in Malaysia. One link is set up between the top of the microwave lab and Balai Cerapan at UTM, Skudai, Johor Baru. The distance between the links is $1.3 \mathrm{~km}$. The second link was set between the top of the microwave lab and a Base Transmit Station (BTS) Tower. The distance between these two links is $0.3 \mathrm{~km}$. Both links are horizontal polarized and antenna size 
is $0.6 \mathrm{~m}$ respectively. The two antennas are well protected with radomes from the effect of wet antenna conditions. The programmed gain control outcome of the antenna is associated with a data acquisition card on a PC to examining the data and the interim was set to 1 -sec. The recorded information at that point saved into databank composed by programming $\mathrm{C}$ language. The measurement was performed over a length of thirty-six months and acceptable information accessibility of $99.95 \%$ was accomplished. A tipping-bucket $\mathrm{RG}$ check with a $0.2 \mathrm{~mm}$ tip size was established on a similar rooftop. The RG measure included a period stamp for each tip with 0.1-second goals [22-24].

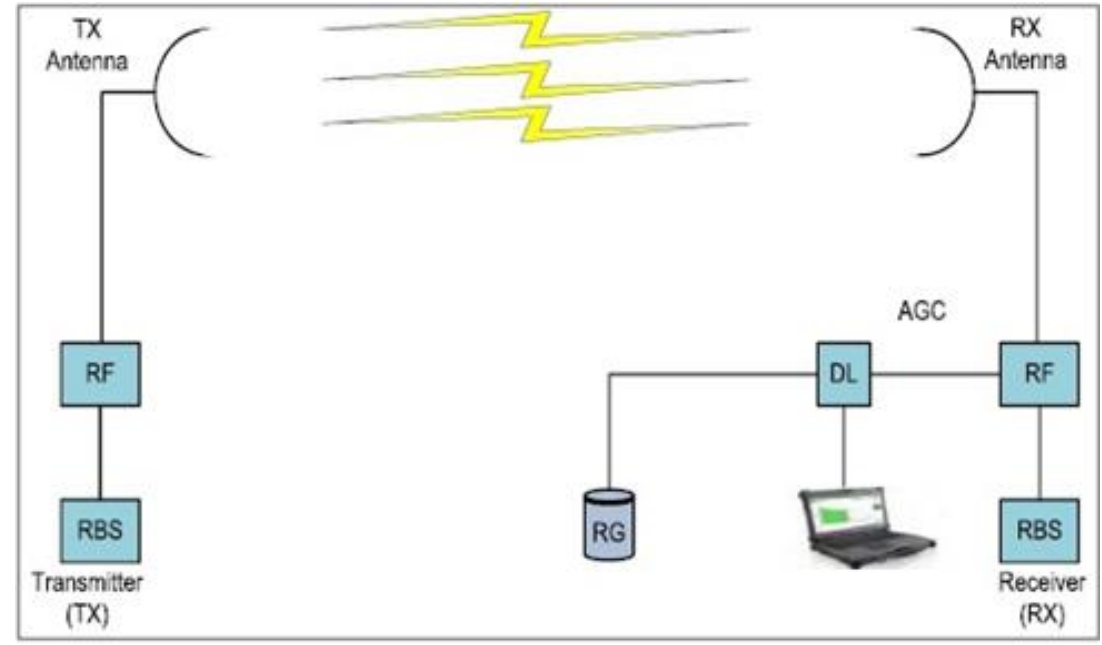

Figure 3. Design outline of the experiment set

Two Ericsson links were set up at the operating frequency of $26 \mathrm{GHz}$ in the university premises at Johor Bahru city in Malaysia. One link is set up between the top of the microwave lab and Balai Cerapan at UTM, Skudai, Johor Baru. The distance between the links is $1.3 \mathrm{~km}$. The second link was set between the top of the microwave lab and a Base Transmit Station (BTS) Tower. The distance between these two links is 0.3 $\mathrm{km}$. Both links are horizontal polarized and antenna size is $0.6 \mathrm{~m}$ respectively. The two antennas are well protected with radomes from the effect of wet antenna conditions. The programmed gain control outcome of the antenna is associated with a data acquisition card on a PC to examining the data and the interim was set to 1 -sec. The recorded information at that point saved into databank composed by programming $\mathrm{C}$ language. The measurement was performed over a length of thirty-six months and acceptable information accessibility of $99.95 \%$ was accomplished. A tipping-bucket RG check with a $0.2 \mathrm{~mm}$ tip size was established on a similar rooftop. The RG measure included a period stamp for each tip with 0.1-second goals [22-24].

\section{RESULTS AND DISCUSSION}

Precipitation intensity rate $\mathrm{R}_{0.01 \%}$ is a very important specification to estimate the signal fading in $\mathrm{dB}$ due to precipitation for a link at particular areas. The measurement period carried on from June 2015 to May 2018 at the university campus, the CCDF rain rate is presented in Figure 4. Recently the precipitation rate, $\mathrm{R}_{0.01}$ is $90 \mathrm{~mm} /$ hour recommended by ITU for Malaysia [25]. The measured rain rate is also compared to the latest version of the ITU-R P.837-7 [1]. It shows that the rain rate of the ITU-R model at $0.1 \%$ and $0.01 \%$ has underestimated the measured rain rate by $12 \mathrm{~mm} / \mathrm{h}$ and $26 \mathrm{~mm} / \mathrm{h}$ respectively. At $0.001 \%$ has overestimated the measured rain rate by $40.8 \mathrm{~mm} / \mathrm{h}$. As a consequence, budget estimation for a link produces serious miscalculation especially at a higher operating frequency for $5 \mathrm{G}$ applications.

The rain attenuation is predicted using ITU-R, AbdulRahman, Lin and da Silva Mello models based on (3-4, (7-12) and presented in Figure 5. The measured rain rate at $\mathrm{R}_{0.01 \%}$ of $116 \mathrm{~mm} / \mathrm{h}$ and path length of $300 \mathrm{~m}$ are considered for prediction. The frequency is considered $26 \mathrm{GHz}$ with horizontal polarization. These predicted attenuations are compared with one-year measured attenuation in UTM [22]. From Figure 5, it indicates that the predicted attenuation results by ITU-R overestimated at $0.001 \%$ and $0.01 \%$ by $14.91 \mathrm{~dB}$ and $3.63 \mathrm{~dB}$ respectively. At $0.1 \%$ ITU-R shows close estimation by $0.48 \mathrm{~dB}$. Da Silva Mello model shows very high overestimated compared to the measured attenuation for short path length. The results are at $0.001 \%, 0.01 \%$ and $0.1 \%$ by $98.58 \mathrm{~dB}, 56.8 \mathrm{~dB}$ and $11.57 \mathrm{~dB}$ respectively. On the other side, 
the AbdulRahman model and Lin model shows underestimated compared to the measured attenuation. For AbdulRahman model at $0.001 \%, 0.01 \%$ and $0.1 \%$ by $6.75 \mathrm{~dB}, 5.37 \mathrm{~dB}$ and $3.88 \mathrm{~dB}$ respectively and almost similar results for Lin model. None of the predictions reflects the measurement accurately at $300 \mathrm{~m}$ path length.

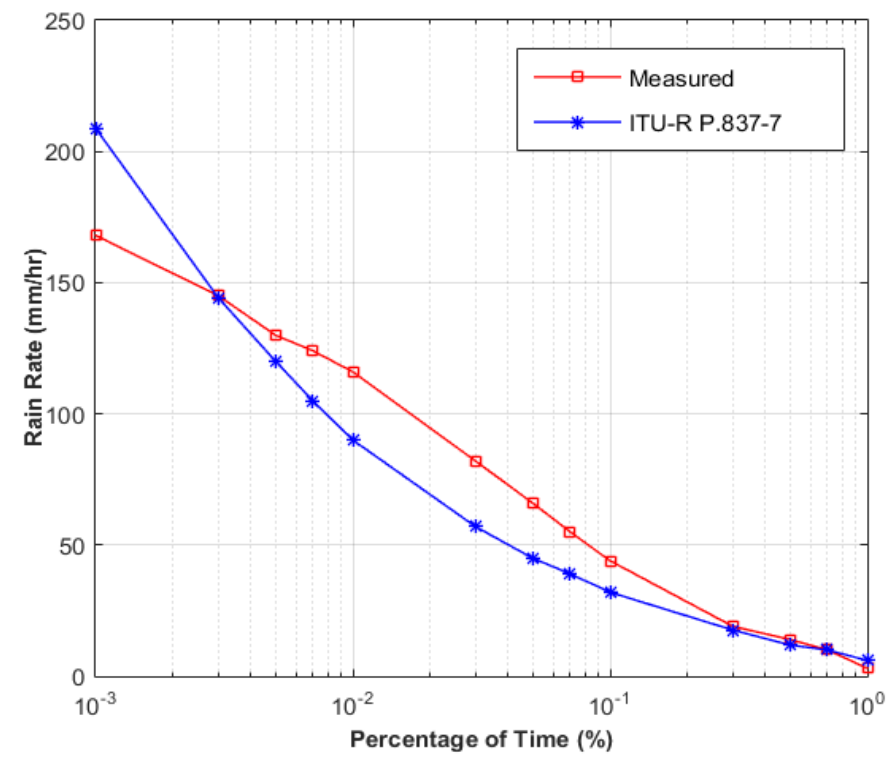

Figure 4. The complementary cumulative distribution function (CCDF) of rain intensity.

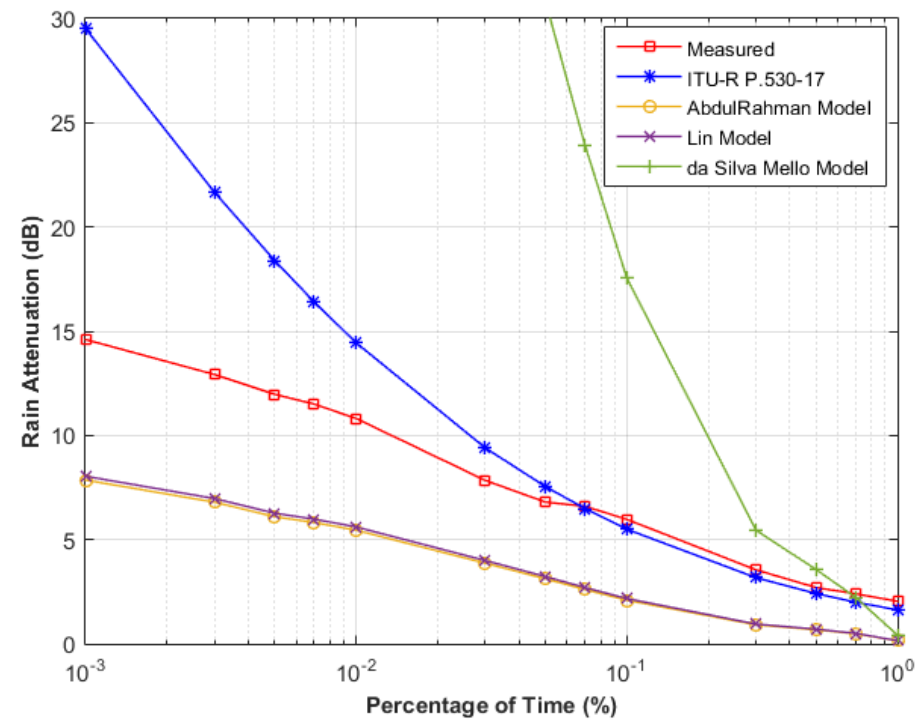

Figure 5. Comparison between measured attenuation with different attenuation prediction models at $26 \mathrm{GHz}$ of frequency horizontal polarized for $300 \mathrm{~m}$ of path length.

The rain attenuation is predicted using ITU-R, AbdulRahman, Lin and da Silva Mello models based on (3-4, 7-12) and presented in Figure 6. The measured rain rate at $\mathrm{R}_{0.01 \%}$ of $116 \mathrm{~mm} / \mathrm{h}$ and path length of 1.3 $\mathrm{km}$ are considered for prediction. The frequency is considered $26 \mathrm{GHz}$ with horizontal polarization. These predicted attenuations are compared with one year of measured attenuation in UTM [24].

From the presented results shown in Figure 6, it is noted that the predicted attenuation results by ITU-R overestimated at $0.001 \%$ by $12.37 \mathrm{~dB}$, at $0.01 \%$ and $0.1 \%$ underestimated by $5.45 \mathrm{~dB}$ and $5.13 \mathrm{~dB}$ respectively. AbdulRahman, Lin and Da Silva Mello model shows underestimated compared to the measured attenuation for path length $1.3 \mathrm{~km}$. The results for Abdul Rahman model are at $0.001 \%, 0.01 \%$ and $0.1 \%$ by 
$15.98 \mathrm{~dB}, 13.18 \mathrm{~dB}$ and $8.02 \mathrm{~dB}$ respectively. Lin model shows less underestimated compared to the measured attenuation. The results for Lin model are at $0.001 \%, 0.01 \%$ and $0.1 \%$ by $13.15 \mathrm{~dB}, 10.67 \mathrm{~dB}$ and $6.74 \mathrm{~dB}$ respectively. Da Silva Mello model shows close estimation compared to the measured attenuation. The results for Mello model are at $0.001 \%, 0.01 \%$ and $0.1 \%$ by $9.09 \mathrm{~dB}, 7.41 \mathrm{~dB}$ and $4.75 \mathrm{~dB}$ respectively.

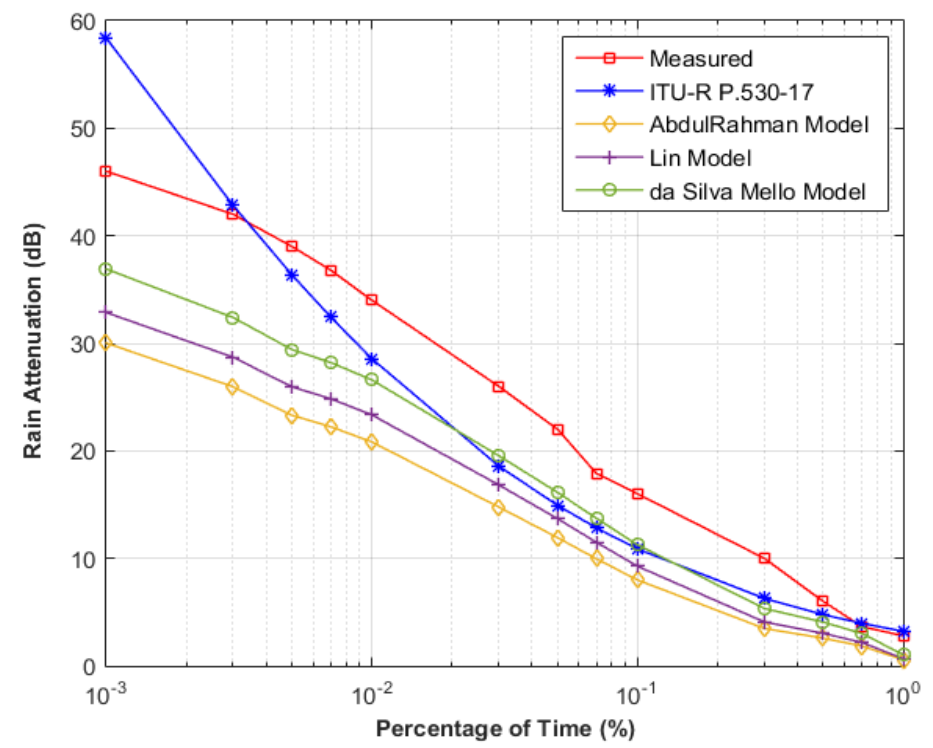

Figure 6. Comparison between measured attenuation with different attenuation prediction models at $26 \mathrm{GHz}$ of frequency horizontal polarized for $1.3 \mathrm{~km}$ of path length

\section{CONCLUSION}

Attenuation caused by the rain of an mm-wave link faces a tremendous challenge to signal accessibility for 5G networks operating in tropical regions. Different models are proposed to predict rain attenuation, however recent measurements show huge discrepancies with predictions for short ranges of path lengths at mm-wave. The path reduction factor is the main parameter in the prediction model for predicting total attenuation from specific rain attenuation. This paper investigated path reduction factor models, which have been proposed by ITU-R P530-17, AbdulRahman, Lin and Da Silva Mello for the prediction of rain attenuation. For path length less than $1 \mathrm{~km}$, it is observed that the value of reduction factor is almost constant with value 1 for AbdulRahman, Lin and da Silva Mello Model, while it shows the value of $r$ increases exponentially for ITU-R. For path length longer than $1 \mathrm{~km}$, it is observed that the value of reduction factor is almost linearly decreasing with the increase of path length for AbdulRahman, da Silva Mello and Lin model, while it shows the value of reduction factor exponentially decreasing with the increase of path length for ITU-R model.

A comparison was made between these models based on rain attenuation data measured at $26 \mathrm{GHz}$ at $300 \mathrm{~m}$ and $1.3 \mathrm{~km}$ path lengths in Malaysia. It indicates that the ITU-R and Da Silva Mello model prediction overestimates the measured attenuation for $300 \mathrm{~m}$ path length. While AbdulRahman and Lin model underestimates compared to the measured attenuation. None of the predictions reflects the measurement accurately at $300 \mathrm{~m}$ path length. For a $1.3 \mathrm{~km}$ link, all models are found close to the measured attenuation with few $\mathrm{dB}$ underestimation. At $0.003 \%$, ITU-R predicts the measurement with correct accuracy and overestimates for lower percentages. All models are found to predict rain attenuation at $1.3 \mathrm{~km}$ paths with minimum errors, while tremendous discrepancies are observed to predict for $300 \mathrm{~m}$ path lengths. Hence it is highly recommended to further investigate the reduction factor model to the accurate prediction for $5 \mathrm{G}$ short path links less than $1 \mathrm{~km}$ operating at $\mathrm{mm}$-wave.

\section{ACKNOWLEDGEMENTS}

This work has been funded by the Ministry of Education Malaysia and Universiti Teknologi Malaysia under "FRGS" Vot. No. RJ130000.7823.4F958 and “IIIG” Vot. No. 01M28. 


\section{REFERENCES}

[1] A. Al-Saman, M. Mohamed, Y. Ai, M. Cheffena, M. H. Azmi and T. A. Rahman, "Rain Attenuation Measurements and Analysis at 73 GHz E-Band Link in Tropical Region," in IEEE Communications Letters, March 2020.

[2] L. Luini, G. Roveda, M. Zaffaroni, M. Costa and C. G. Riva, "The Impact of Rain on Short E-Band Radio Links for 5G Mobile Systems: Experimental Results and Prediction Models," in IEEE Transactions on Antennas and Propagation, vol. 68, no. 4, pp. 3124-3134, April 2020.

[3] S. N. Livieratos and P. G. Cottis, "Rain Attenuation Along Terrestrial Millimeter Wave Links: A New Prediction Method Based on Supervised Machine Learning," in IEEE Access, vol. 7, pp. 138745-138756, 2019.

[4] T. S. Rappaport, Y. Xing, G. R. MacCartney, A. F. Molisch, E. Mellios and J. Zhang, "Overview of Millimeter Wave Communications for Fifth-Generation (5G) Wireless Networks-With a Focus on Propagation Models," in IEEE Transactions on Antennas and Propagation, vol. 65, no. 12, pp. 6213-6230, Dec. 2017.

[5] H. Y. Lam, L. Luini, J. Din, M. J. Alhilali, S. L. Jong and F. Cuervo, "Impact of rain attenuation on 5G millimeter wave communication systems in equatorial Malaysia investigated through disdrometer data," 2017 11th European Conference on Antennas and Propagation (EUCAP), Paris, 2017, pp. 1793-1797.

[6] Ibraheem Shayea, Tharek Abd. Rahman, Marwan Hadri Azmi, Arsany Arsad, "Rain attenuation of millimetre wave above $10 \mathrm{GHz}$ for terrestrial links in tropical regions," Transactions on Emerging Telecommunications Technologies, vol. 29, no. 8, Aug 2018.

[7] M. Ghanim, M. Alhilali, J. Din and H. Lam, "Rain attenuation statistics over 5G millimetre wave links in Malaysia," Indonesian Journal of Electrical Engineering and Computer Science (IJEECS), vol. 14, no. 2, pp. 1012-1017, 2019.

[8] ITU-R. P. Series, "Specific attenuation model for rain for use in prediction methods," Recommendation ITU-R P. 838-3, pp. 1-8, 2005.

[9] R. Ghiani, L. Luini and A. Fanti, "A physically based rain attenuation model for terrestrial links," in Radio Science, vol. 52, no. 8, pp. 972-980, Aug. 2017.

[10] M. Alhilali, M. Ghanim, J. Din and H. Lam, "A methodology for precise estimation of rain attenuation on terrestrial millimetre wave links from raindrop size distribution measurements," TELKOMNIKA Telecommunication Computing Electronics and Control, vol. 17, no. 5, pp. 2139-2146, Oct 2019.

[11] I. Shayea, et al., "Rain attenuation and worst month statistics verification and modeling for 5G radio link system at 26 GHz in Malaysia," Transactions on Emerging Telecommunications Technologies, vol. 30, no. 12, Dec 2019.

[12] S. Shrestha, J. Lee, S. Kim and DY. Choi, "Rain attenuation over Terrestrial Microwave links at 18GHz as compared with Prediction by ITU-R Model," Journal of Information and Communication Convergence Engineering, vol. 15, no. 3, pp. 143-150, Sep. 2017.

[13] Rafiqul M. D. Islam, Yusuf A. Abdulrahman, Tharek A. Rahman, "An improved ITU-R rain attenuation prediction model over terrestrial microwave links in tropical region," EURASIP Journal on Wireless Communications and Networking, Article no.189, 2012.

[14] Sujan Shrestha, Dong-You Choi, "Rain attenuation statistics over millimeter wave bands in South Korea", Journal of Atmospheric and Solar-Terrestrial Physics, vol. 152-153, pp. 1-10, January 2017.

[15] I. Shayea, T. Abd. Rahman, M. Hadri Azmi and M. R. Islam, "Real Measurement Study for Rain Rate and Rain Attenuation Conducted Over $26 \mathrm{GHz}$ Microwave 5G Link System in Malaysia," in IEEE Access, vol. 6, pp. 19044-19064, 2018.

[16] J. Huang, Y. Cao, X. Raimundo, A. Cheema and S. Salous, "Rain Statistics Investigation and Rain Attenuation Modeling for Millimeter Wave Short-Range Fixed Links," in IEEE Access, vol. 7, pp. 156110-156120, 2019.

[17] ITU-Recommendation P.530-17: Propagation data and prediction methods required for the design of terrestrial lineof-sight systems, ITU-R P530-17, 2017.

[18] A. Y. Abdulrahman, T. A. Rahman, S. K. A. Rahim \& M. R. Ul Islam, "Empirically derived path reduction factor for terrestrial microwave links operating at $15 \mathrm{GHz}$ in Peninsula Malaysia," Journal of Electromagnetic Waves and Applications, vol. 25, no. 1, pp. 23-37, 2011.

[19] S. Lin, "11-GHz radio: nationwide long-term rain rate statistics and empirical calculation of 11-GHz microwave rain attenuation," Bell System Technical Journal, vol. 56, no. 9, pp. 1581-1604, 1977.

[20] L. A. R. Da Silva Mello, M. S. Pontes, R. M. De Souza and N. A. Perez Garcia, "Prediction of rain attenuation in terrestrial links using full rainfall rate distribution," in Electronics Letters, vol. 43, no. 25, pp. 1442-1443, 6 Dec. 2007.

[21] L. A. R. da Silva Mello, M. S. Pontes and R. S. L. de Souza, "New method for the prediction of rain attenuation in terrestrial links using the concept of effective rainfall rate," 2007 SBMO/IEEE MTT-S International Microwave and Optoelectronics Conference, Brazil, pp. 899-901, 2007.

[22] M. R. Islam and A. R. Tharek, "Propagation study of microwave signals based on rain attenuation data at 26 GHz and $38 \mathrm{GHz}$ measured in Malaysia," 1999 Asia Pacific Microwave Conference. APMC'99. Microwaves Enter the 21st Century. Conference Proceedings (Cat. No.99TH8473), Singapore, vol. 3, pp. 602-605, 1999

[23] M. D'Amico, S. L. Jong and C. Riva, "Tipping bucket data processing for propagation application," 2013 7th European Conference on Antennas and Propagation (EuCAP), Gothenburg, pp. 256-260, 2013.

[24] K. Ulaganathen, A. R. Tharek, R. M. Islam and K. Abdullah, "Case study of rain attenuation at 26 GHz in tropical region (Malaysia) for terrestrial link," 2015 IEEE 12th Malaysia International Conference on Communications (MICC), Kuching, pp. 252-257, 2015.

[25] ITU-R. P. Series, "Characteristics of precipitation for propagation modelling," Recommendation ITU-R P. 837-7, pp. 1-8, 2017. 